\title{
Editorial
}

\section{Phytogenics as an Alternative to Antibiotics: Chemical Mechanism behind Antimicrobial Activity of Essential Oils}

\author{
Alison Ferver, $\mathbf{B S c}^{1}$, Sami Dridi, $\mathbf{P h D}^{2 *}$ \\ 'Department of Animal Science, College of Agricultural Science, The Pennsylvania State University, PA I6802, USA \\ ${ }^{2}$ Department of Poultry Science, Division of Agriculture, University of Arkansas, Fayetteville, AR 7270 I, USA

\section{"Corresponding author} \\ Sami Dridi, PhD \\ Center of Excellence for Poultry Science, University of Arkansas, I 260 W, Maple Street, Fayetteville AR 7270I, USA; Tel. (479)-575-2583; Fax: (479)-575-7I39; \\ E-mail: dridi@uark.edu
}

\section{Article information}

Received: October $7^{\text {th }}, 2018$; Accepted: October II th 2018 ; Published: October $15^{\text {th }}, 2018$

\section{Cite this article}

Ferver A, Dridi S. Phytogenics as an alternative to antibiotics: Chemical mechanism behind antimicrobial activity of essential oils. Adv Food Technol Nutr Sci Open J. 20I8; 4(2): el-e3. doi: I0.17I40/AFTNSOJ-4-e0I2

\section{INTRODUCTION}

Since the 1950s, antibiotics have been the "silver bullet" for the Otreatment of diseases in both the medical and livestock industries. The use of subtherapeutic antibiotics in broilers not only prevents disease outbreaks but also increases meat yield and feed conversion. ${ }^{1}$ The mode of action for the added growth promoter effects of antibiotics stems from their ability to control microbial populations in the gut, decreasing toxic microbial byproducts and limiting competition for nutrients in the gastrointestinal tract (GIT). ${ }^{2,3}$ These growth promoting effects have made antibiotics a common feed additive in the poultry industry. ${ }^{4}$ However, decades of exposing microorganisms to low doses of antibiotics has created a selection pressure for antibiotic-resistant bacteria. ${ }^{5}$ In a 2017 study in Ghana, over sixty percent of Staphylococci isolates from poultry farms and farm workers were resistant to multiple antibiotics, including tetracycline, one of the most common antibiotics in the poultry industry. ${ }^{6}$ The European Union banned the use of food animal growth-promoting antibiotics in 1986. In the USA, the guidelines for industry issued by the Center for Veterinary Medicines of the Food and Drug Administration (FDA, 2012) recommend use of antibiotics only for the prevention, control and treatment of infections in animals but not for the promotion of growth, increased performance, and improved feed efficiency. Alternatives to antibiotics are, therefore, needed in order to continue the efficiency and sustainability of the poultry production. A promising alternative is phytogenic essential oil. In this editorial, we will review how the structure of phytochemicals within essential oils contributes to the antimicrobial activity and growth promotion in broilers.

\section{ANTIMICROBIAL MECHANISM OF ESSENTIAL OILS |}

Derived from plants and herbs, essential oils contain antimicrobial phytochemicals that modulate microbial populations in the GIT to prevent disease and promote growth, even after vaccination or when challenged with high doses of microbes, including Clostridium perfringens. ${ }^{7-9}$ Terpenoids act as non-specific bactericidal antimicrobials at high doses by altering the structure and function of the cytoplasmic membrane and disrupting membrane protein binding and ATP synthesis. ${ }^{10}$ Terpenoids ability to interfere with the phospholipid bilayer structure and integrity is due to the positioning of the hydroxyl group and the hydrophobicity of the benzene ring and substituents. ${ }^{11}$ Carvacrol and thymol are terpenoids in essential oils from herbs like thyme and oregano that have become increasingly more popular as feed additives in the poultry industry. ${ }^{12}$ They are both substituted phenols but differ in the location of the hydroxyl group on the aromatic ring. As seen in Figure 1, carvacrol has a hydroxyl group bonded in the ortho position relative to the methyl group and thymol has the hydroxyl in the meta position.

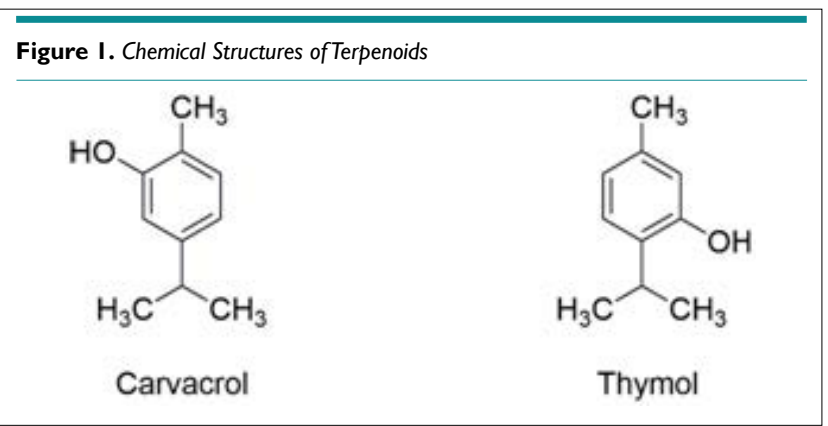

When comparing the antimicrobial activity of these terpenoids, carvacrol differs in its mode of action due to the dif- 
doi: $10.1093 / \mathrm{ps} / 84.4 .634$

2. Lan Y, Verstegen M, Tamminga S, Williams B. The role of the commensal gut microbial community in broiler chickens. Worlds Poultry Science Journal. 2005; 61(01): 95-104. doi: 10.1079/wps200445

3. Lin J, Hunkapiller AA, Layton AC, Chang Y-J, Robbins KR. Response of intestinal microbiota to antibiotic growth promoters in chickens. Foodborne Pathog Dis. 2013; 10(4): 331-337. doi: 10.1089/ fpd.2012.1348

It also interferes with the holding of membrane proteins, which contributes to the leakage of ions and intracellular molecules such as ATP. ${ }^{14}$ Carvacrol also increases membrane permeability. However, the positioning of the hydroxyl group near methyl rather than isopropyl, as in the case of thymol, enables the molecule to act as a proton exchanger and more easily form hydrogen bonds. ${ }^{15,16}$ By bringing $\mathrm{H}^{+}$into the cytoplasm and facilitating the movement of $\mathrm{K}^{+}$out, the $\mathrm{H}^{+}$gradient needed for ATP synthesis is disrupted. When exposed to carvacrol, the ATP pool within the cell is depleted and there is an increase in intracellular ATP. ${ }^{17}$ In the case of Gram negative bacteria, the hydrogen bonding capacity of carvacrol and its small size allows it to pass more readily through the outer membrane via porins. ${ }^{11,17,18}$ This allows access to the cytoplasmic membrane and aids in the antimicrobial capacity of carvacrol. The significance of the free hydroxyl group and delocalized electron system is demonstrated by the lack of antimicrobial capacity of carvacryl acetate and menthol when compared to carvacrol. Carvacryl acetate shares the hydrophobic properties of carvacrol but lacks the hydroxyl group, replaced with a carboxylic acid. The inability to form hydrogen bonds reduces the molecules ability to disrupt the integrity of the cytoplasmic membrane. In menthol, the benzene ring is replaced with a 6-carbon single bonded ring, removing the delocalized electron system. This inhibits the molecules proton exchanging abilities. ${ }^{19}$

When analyzing the use of thymol and carvacrol as feed additives, their stability at varying $\mathrm{pH}$ is crucial to their effectiveness in the GIT. In the broiler GIT, the $\mathrm{pH}$ ranges from 2.5 to $8 .{ }^{20}$ When compared to other essential oil components, carvacrol and thymol maintained antimicrobial activity against multiple organisms after exposure to $\mathrm{pH}$ values from 2 to $7 .{ }^{21}$ The ability of essential oils to decrease microbial population in the GIT results in less competition for nutrient absorption, decreased microbe fermentation, and a more stable $\mathrm{pH}$. In terms of growth promotion, these terpenoids have been shown to increase body weight and average daily gain in a manner comparable to antibiotic growth promoters. ${ }^{22,23}$ The reduced fermentation and $\mathrm{pH}$ stability decreases the decarboxylation of limiting amino acids and provides optimal conditions for digestive enzyme activity, resulting in an increased digestibility of nitrogen and availability of nutrients, promoting overall growth. ${ }^{24,25}$

\section{CONFLICTS OF INTEREST}

The authors declare that they have no conflicts of interest.

\section{REFERENCES}

1. Dibner JJ, Richards JD. Antibiotic growth promoters in agriculture: History and mode of action. Poult Sci. 2005; 84(4): 634-643.
4. Mehdi Y, Létourneau-Montminy MP, Gaucher ML, et al. Use of antibiotics in broiler production: Global impacts and alternatives. Anim Nutr. 2018; 4(2): 170-178. doi: 10.1016/j.aninu.2018.03.002

5. Blair JMA, Webber MA, Baylay AJ, Ogbolu DO, Piddock LJV. Molecular mechanisms of antibiotic resistance. Nat Rev Microbiol. 2014; 13(1): 42-51. doi: 10.1038/nrmicro3380

6. Boamah VE, Agyare C, Odoi H, et al. Prevalence and antibiotic resistance of coagulase-negative Staphylococci isolated from poultry farms in three regions of Ghana. Infect Drug Resist. 2017; 10: 175-183. doi: $10.2147 /$ idr.s136349

7. Mitsch P, Zitterl-Eglseer K, Kohler B, et al. The effect of two different blends of essential oil components on the proliferation of Clostridium perfringens in the intestines of broiler chickens. Poult Sci. 2004; 83(4): 669-675. doi: $10.1093 /$ ps/83.4.669

8. Oviedo-Rondon EO, Hume ME, Hernandez C, Clemente-Hernandez S. Intestinal microbial ecology of broilers vaccinated and challenged with mixed Eimeria species, and supplemented with essential oil blends. Poult Sci. 2006; 85(5): 854-860. doi: 10.1093/ ps/85.5.854

9. Steiner T. Phytogenics in Animal Nutrition: Natural Concepts to Optimize Gut Health and Performance. Nottingham, England: Nottingham University Press. 2010.

10. Suresh G, Das RK, Brar SK, et al. Alternatives to antibiotics in poultry feed: Molecular perspectives. Crit Rev Microbiol. 2018; 44(3): 318-335. doi: 10.1080/1040841x.2017.1373062

11. Griffin SG, Wyllie SG, Markham JL, Leach DN. The role of structure and molecular properties of terpenoids in determining their antimicrobial activity. Flavour and Fragrance Journal. 1999; 14(5): 322-332. doi: 10.1002/(sici)1099-1026(199909/10)14:5<322::aidffj $837>3.0 . \operatorname{co} ; 2-4$

12. Memar MY, Raei P, Alizadeh N, et al. Carvacrol and thymol: strong antimicrobial agents against resistant isolates. Reviews in Medical Microbiology. 2017; 28(2): 63-68. doi: 10.1097/ mrm.0000000000000100

13. Burt S. Essential oils: Their antibacterial properties and potential applications in foods - a review. International Journal of Food Microbiology. 2004; 94(3): 223-253. doi: 10.1016/j.ijfoodmicro.2004.03.022

14. Nazzaro F, Fratianni F, Martino LD, Coppola R, Feo VD. Ef- 
fect of essential oils on pathogenic bacteria. Pharmacenticals (Basel). 2013; 6(12): 1451-1474. doi: 10.3390/ph6121451

15. Veldhuizen EJ, Zweijtzer C, Burt SA, et al. Structural requirements for the antimicrobial activity of carvacrol. I Agric Food Chem. 2006; 54(5): 1874-1879. doi: 10.1021/jf052564y

16. Ultee A, Bennik MHJ, Moezelaar R. The phenolic hydroxyl group of carvacrol is essential for action against the food-borne pathogen bacillus cereus. Appl Environ Microbiol. 2002; 68(4): 1561 1568. doi: $10.1128 /$ aem.68.4.1561-1568.2002

17. Helander IM, Alakomi HL, Latva-Kala K, et al. Characterization of the action of selected essential oil components on gramnegative bacteria. J Agric Food Chem. 1998; 46(9): 3590-3595. doi: $10.1021 /$ jf980154m

18. Arfa AB, Combes S, Preziosi-Belloy L, Gontard N, Chalier P. Antimicrobial activity of carvacrol related to its chemical structure. Lett Appl Microbiol. 2006; 43(2): 149-154. doi: 10.1111/j.1472 765x.2006.01938.x

19. Garcia-Salinas S, Elizondo H, Arruebo M, Mendoza G, Irusta $\mathrm{S}$. Evaluation of the antimicrobial activity and cytotoxicity of different components of natural origin present in essential oils. Molecules. 2018; 23(6). doi: 10.3390/molecules23061399
20. Gauthier R. Intestinal health, the key to productivity: The case of organic acids. 2002.

21. Si W, Gong J, Tsao R, et al. Antimicrobial activity of essential oils and structurally related synthetic food additives towards selected pathogenic and beneficial gut bacteria. I Appl Microbiol. 2006; 100(2): 296-305. doi: 10.1111/j.1365-2672.2005.02789.x

22. Mathlouthi N, Bouzaienne T, Oueslati I, et al. Use of rosemary, oregano, and a commercial blend of essential oils in broiler chickens: In vitro antimicrobial activities and effects on growth performance. J Anim Sci. 2012; 90(3): 813-823. doi: 10.2527/jas.20103646

23. Hashemi S, Davoodi H. Phytogenics as new class of feed additive in poultry industry. Journal of Animal and Veterinary Advances. 2010; 9(17): 2295-2304. doi: 10.3923/javaa.2010.2295.2304

24. Jamroz D, Orda J, Kamel C, et al. The influence of phytogenic extracts on performance,nutrient digestibility, carcass characteristics, and gut microbial status in broiler chickens. Journal of Animal and Feed Sciences. 2003; 12(3): 583-596. doi: 10.22358/ jafs/67752/2003

25. Zhai H, Liu H, Wang S, Wu J, Kluenter AM. Potential of essential oils for poultry and pigs. Animal Nutrition. 2018; 4(2): 179-186. doi: 10.1016/j.aninu.2018.01.005 